\title{
Comparison of Diamond Growth with Different Gas Mixtures in Microwave Plasma Asssited Chemical Vapor Deposition (MWCVD)
}

\author{
Evaldo J. Corat*, Neidenei G. Ferreira, Nélia F. Leite, Vladimir J. Trava-Airoldi \\ Instituto Nacional de Pesquisas Espaciais \\ C.P. 515, 12201-970 São José dos Campos - SP, Brazil
}

Received: January 02, 2002; Revised: September 30, 2002

\begin{abstract}
In this work we study the influence of oxygen addition to several halocarbon-hydrogen gas systems. Diamond growth have been performed in a high power density MWCVD reactor built in our laboratory. The growth experiments are monitored by argon actinometry as a reference to plasma temperature and atomic hydrogen production, and by mass spectrometry to compare the exhaust gas composition. Atomic hydrogen actinometry revealed that the halogen presence in the gas phase is responsible for a considerable increase of atomic hydrogen concentration in the gas phase. Mass spectrometry shows similar results for all gas mixtures tested. Growth studies with oxygen addition to $\mathrm{CF}_{4} / \mathrm{H}_{2}, \mathrm{CCl}_{4} / \mathrm{H}_{2}, \mathrm{CCl}_{2} \mathrm{~F}_{2} / \mathrm{H}_{2}$ and $\mathrm{CH}_{3} \mathrm{Cl} / \mathrm{H}_{2}$ reveals that oxygen increases the carbon solubility in the gas phase but no better diamond growth conditions were found. Halogens are not, per se, eligible for diamond growth. All the possible advantages, as the higher production of atomic hydrogen, have been suppressed by the low carbon solubility in the gas phase, even when oxygen is added. The diamond growth with small amount of $\mathrm{CF}_{4}$ added to $\mathrm{CH}_{4} / \mathrm{H}_{2}$ mixture is not aggressive to the apparatus but brings several advantages to the process.
\end{abstract}

Keywords: diamond, chemical vapor deposition, halogen, actinometry

\section{Introduction}

The growth of polycrystalline diamond films by chemical vapor deposition (CVD) has been considerably developed $^{1,2}$. Many features of this development are the subject of many good reviews that show its importance from the scientific and technological viewpoints ${ }^{3}$. Many aspects on gas phase chemistry and some of the surface processes have been uncovered, mainly for the C-H and C-H-O systems ${ }^{4,5}$. Prospects for hybrid activation methods have been considered for growth rate enhancement ${ }^{6}$.

The introduction of halogens in the precursor gas mixture has also shown some specific characteristics and advantages $^{7-11}$. Lower gas activation, growths at lower substrate temperatures, better diamond quality at higher carbon content and also higher growth rates have been reported with the use of halogens. However, very little has been revealed about the influence of halogens on the gas phase. The study of the growth rate for diamond growth with halogens as a function of substrate temperature reveals an activation en- ergy in the range from 9 to $11 \mathrm{kcal} / \mathrm{mol}$, which is very similar to the growth in C-H-O systems or in the C-H systems with high atomic hydrogen concentration ${ }^{8}$. Recently, Petherbridge et al. ${ }^{9}$ reported the activation energy for growth from $\mathrm{CH}_{4} / \mathrm{CO}_{2}$ to be around $6 \mathrm{kcal} / \mathrm{mol}$ and proposed that a new growth mechanism could be responsible for such a low value. However, the comparison of Petherbridge et al. data together with the normalized data collected by Corat et al. ${ }^{12}$ clearly reveals that no new process exists and that diamond growth dependence on substrate temperature is very similar, independently of the gas system used. The different activation energies obtained by different authors are only due to variations on their particular data. The observation of all sets of data together is much more significant and reveals that probably the same limiting step is responsible for the diamond growth activation energy, independently of the gas phase.

Studies of atomic hydrogen actinometry ${ }^{10,11}$ revealed that

*e-mail: corat@las.inpe.br 
the halogen presence in the gas phase is responsible for a considerable increase of atomic hydrogen concentration in the gas phase. This observation could indicate the halogen gas system as a good candidate to decrease the power needed for diamond growth, which would have a beneficial impact on economical aspects of the process. However, besides the higher production of atomic hydrogen as a result of the gas kinetics process, the introduction of halogens brings a gas phase with low carbon solubility. The equilibrium chemistry indicates a large amount of carbon in solid phase and there is the tendency to deposit non-diamond carbon ${ }^{12}$.

In this work we study the influence of oxygen addition to several halocarbon-hydrogen gas systems. The idea of introducing oxygen in these gas systems was to increase the carbon solubility in the gas phase. The advantage of a higher atomic hydrogen production and a gas phase with higher carbon solubility could bring better conditions for diamond growth. In this work we use actinometry of the $\mathrm{H}_{\alpha}$ line to access the relative atomic hydrogen concentration, and exhaust gas mass spectrometry to analyse the stable species formed in the reactor. The increase of the $\mathrm{H}$ atom concentration is confirmed and it further increases with $\mathrm{O}_{2}$ addition. Mass spectrometry shows similar results for all gas mixtures tested. Growth studies with oxygen addition to $\mathrm{CF}_{4} / \mathrm{H}_{2}, \mathrm{CCl}_{4} / \mathrm{H}_{2}, \mathrm{CCl}_{2} \mathrm{~F}_{2} / \mathrm{H}_{2}$ and $\mathrm{CH}_{3} \mathrm{Cl} / \mathrm{H}_{2}$ reveals that oxygen increases the carbon solubility in the gas phase but no better diamond growth conditions were found.

\section{Experimental}

A microwave plasma assisted reactor for diamond growth has been used in these experiments. This reactor operates at $1 \mathrm{~kW}$ microwave power but its cavity has been designed to obtain high power density in the plasma ball, equivalent to more powerful reactors. Four mass flowmeters were used to feed the gas at a total flow rate of $100 \mathrm{sccm}$. Three of then were used for $\mathrm{H}_{2}, \mathrm{O}_{2}$ and argon, respectively, and the fourth was used to feed the halocarbon gas. $\mathrm{CF}_{4}, \mathrm{CCl}_{2} \mathrm{~F}_{2}$ and $\mathrm{CH}_{3} \mathrm{Cl}$ were feed directly from high purity gas cylinders. $\mathrm{CCl}_{4}$ was feed by bubbling hydrogen in the liquid solvent. Argon was used as the actinometer in the actiometry experiments. The halocarbon and oxygen concentrations ranged from 0 to $3 \mathrm{vol} \%$. The system used for optical emission measurements consisted of a lens of $500 \mathrm{~mm}$ focal length for imaging the center of the plasma ball, as sighted by the reactor's lateral window, a monochromator (Jobin Yvon type HRS) and a photomultiplier (RCA type 60R). Relative atomic hydrogen concentrations were recorded as the ratio of the Balmer line $\mathrm{H}_{\alpha}(656.3 \mathrm{~nm})$ to the argon $750,4 \mathrm{~nm}$ line. A chopper and a lockin amplifier (EG\&G Princeton 5110) were used to obtain the signal from the photomultiplier with hgh sensibility. The measurements of the exhaust gas were made using a quadrupole mass spectrometer (Balzers QMG $421 \mathrm{C}$ ).

To resist to halogen attack the reactor had the walls in anodized aluminum and the vacuum system consisted of a fomblim oil mechanical pump. One auxiliary liquid nitrogen trap was used to prevent halogens to be released to atmosphere.

\section{Results and discussion}

\subsection{Characterization of the microwave plasma reactor}

The reactor has been characterized to obtain parameters for the comparison of the experiments with different gas mixtures. With a mixture of $1 \% \mathrm{CH}_{4}$ in $\mathrm{H}_{2}$, at 50 Torr, it was observed that the relative variation of atomic hydrogen concentration, as observed by actinometry, increased linearly reaching a $100 \%$ increase at $1300 \mathrm{~W}$, compared with the relative concentration at $600 \mathrm{~W}$.

A fundamental characteristic in the diagnosis of a plasma for actinometry is the correspondence of the results with the actinometer ${ }^{13}$. For the argon this can be measured by the intensity of emission of the lines in $750 \mathrm{~nm}$ and $811 \mathrm{~nm}$, due, respectively, to the transitions $2 \mathrm{p}_{1} \rightarrow 1 \mathrm{~s}_{2}$ e $2 \mathrm{p}_{9} \rightarrow 1 \mathrm{~s}_{5}$. As described in the literature, the ratio among the intensities of these two lines can be used to analyze the tendency of variation of the plasma electronic temperature. The emission in these two lines was accompanied in all the actinometry experiments. For example, the addition of oxygen to a $\mathrm{CH}_{4} / \mathrm{H}_{2}$ mixture causes a reduction of the plasma temperature, as observed by the reduction of the emission intensity by the actinometer. However, the fact that both argon lines have the same behavior and the ratio of both intensities is constant is an indication of an acceptable variation of the plasma conditions. This good condition was observed for all experiments.

The variation of microwave power varies in the correspondence between the argon lines. The ratio between the emission intensities in 750 and $811 \mathrm{~nm}$ decreases with the power increase (notice that for power variation it is also necessary to vary the pressure in order to keep the microwave cavity oscillating mode). This decrease implicates in a decrease of the electronic temperature of the plasma, since the excitation rate of the level $2 p_{1}$ it is smaller than the one of the $2 \mathrm{p}_{9}$, for smaller electronic temperatures. Therefore, for comparison among the several experiments it is essential the maintenance of the excitation parameters, which were stipulated as pressure of 50 Torr and power of $1000 \mathrm{~W}$.

\subsection{Experiments only with halocarbons and hydrogen}

The actinometry of the atomic hydrogen, for the different mixtures containing halocarbon showed, always, a tendency of expressive increase of the concentration of atomic hydrogen, with the increase of the concentration of the 
halocarbon. Figure 1 shows the relative variation of the intensity of the atomic hydrogen emission lines, considering as reference the intensity with only hydrogen in the reactor. With the addition of methane, it is also observed an increase of the intensity of the line $\mathrm{H}_{\alpha}$, but this is quite discreet compared with observed in Fig. 1. The relative variation is smaller than $20 \%$ for $3 \%$ of methane in hydrogen. Among the halogens, for $3 \%$ of $\mathrm{CF}_{4}$ the relative variation is close to $150 \%$, for $3 \%$ of $\mathrm{CCl}_{2} \mathrm{~F}_{2}$ it is of this same order, and for $\mathrm{CCl}_{4}$, a much more significant increase exists. For $\mathrm{CH}_{3} \mathrm{Cl}$, this relative variation is smaller, of the order of $70 \%$ for $3 \%$ of $\mathrm{CH}_{3} \mathrm{Cl}$

An important detail of these measurements was that the relative variation of atomic hydrogen concentration, measured from the three main emission lines $\left(\mathrm{H}_{\alpha}, \mathrm{H}_{\beta}\right.$ and $\left.\mathrm{H}_{\gamma}\right)$, give similar results. This result indicates that the current control on the experiments guarantees that actinometry is valid for the evaluation of the variation of the atomic hydrogen concentration in the growth atmosphere, even with the halogen addition.

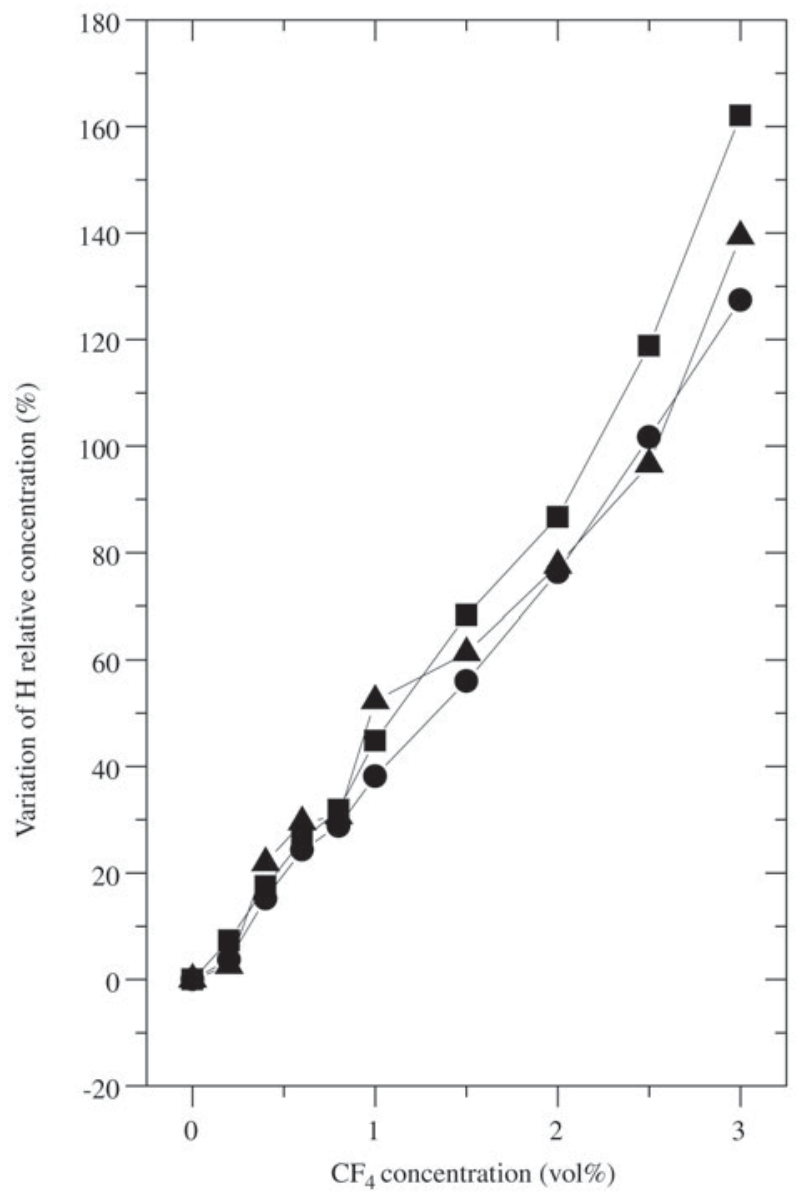

The mass spectrometry shows, for all cases, the transformation of the halocarbons into hydrocarbons and the respective acids, $\mathrm{HF}$ and $\mathrm{HCl}$. Figure 2 shows the concentrations of methane, acetylene and of the acids, with the scales adjusted to evidence the methane and the acetylene, in comparison with the results in a plasma just of methane and hydrogen. Observe that the final concentrations of methane and acetylene are practically the same ones, independently of the gas $\left(\mathrm{CH}_{4}, \mathrm{CF}_{4}, \mathrm{CCl}_{2} \mathrm{~F}_{2}\right.$ and $\left.\mathrm{CCl}_{4}\right)$ in mixture with hydrogen. This demonstrates that the halocarbons completely turned into hydrocarbons and that these reach the equilibrium conditions inside the reactor. Besides the presence of the acids, very probably the concentrations of the stable species on the substrate are very similar, with the several gas mixtures. As the gas inlet is in the upper part of the reactor, it is very probable that the whole conversion of these gases has already happened until they reach the substrate. With the gas inlet close to the substrate and collection of gases by a quartz probe very close to this gas inlet $(2 \mathrm{~mm})$ it was not possible to discriminate the process of conversion

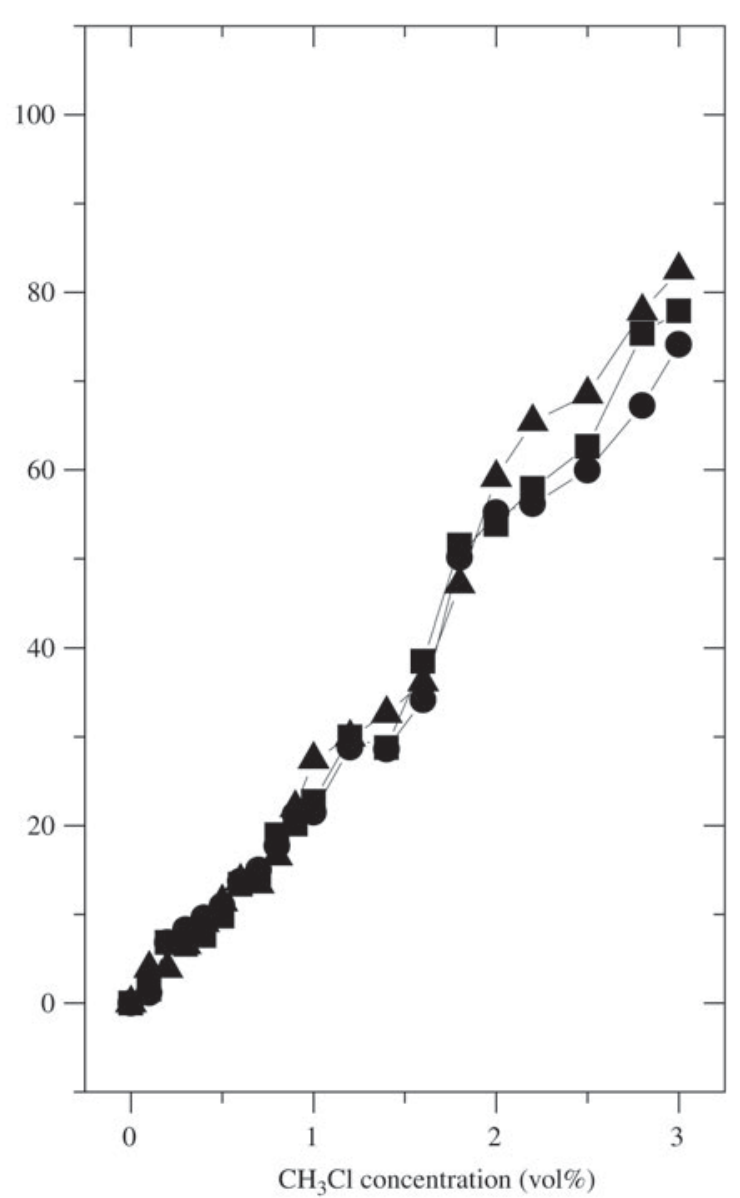

Figure 1. Variation of atomic hydrogen relative concentration with the halogen concentration. a) $\left.\mathrm{CF}_{4} ; \mathrm{b}\right) \mathrm{CH}_{3} \mathrm{Cl}_{\mathbf{0}} \mathbf{\square} \mathrm{H}_{\alpha} ; \boldsymbol{\bullet} \mathrm{H}_{\beta} ; \boldsymbol{\Delta} \mathrm{H}_{\gamma}$. 

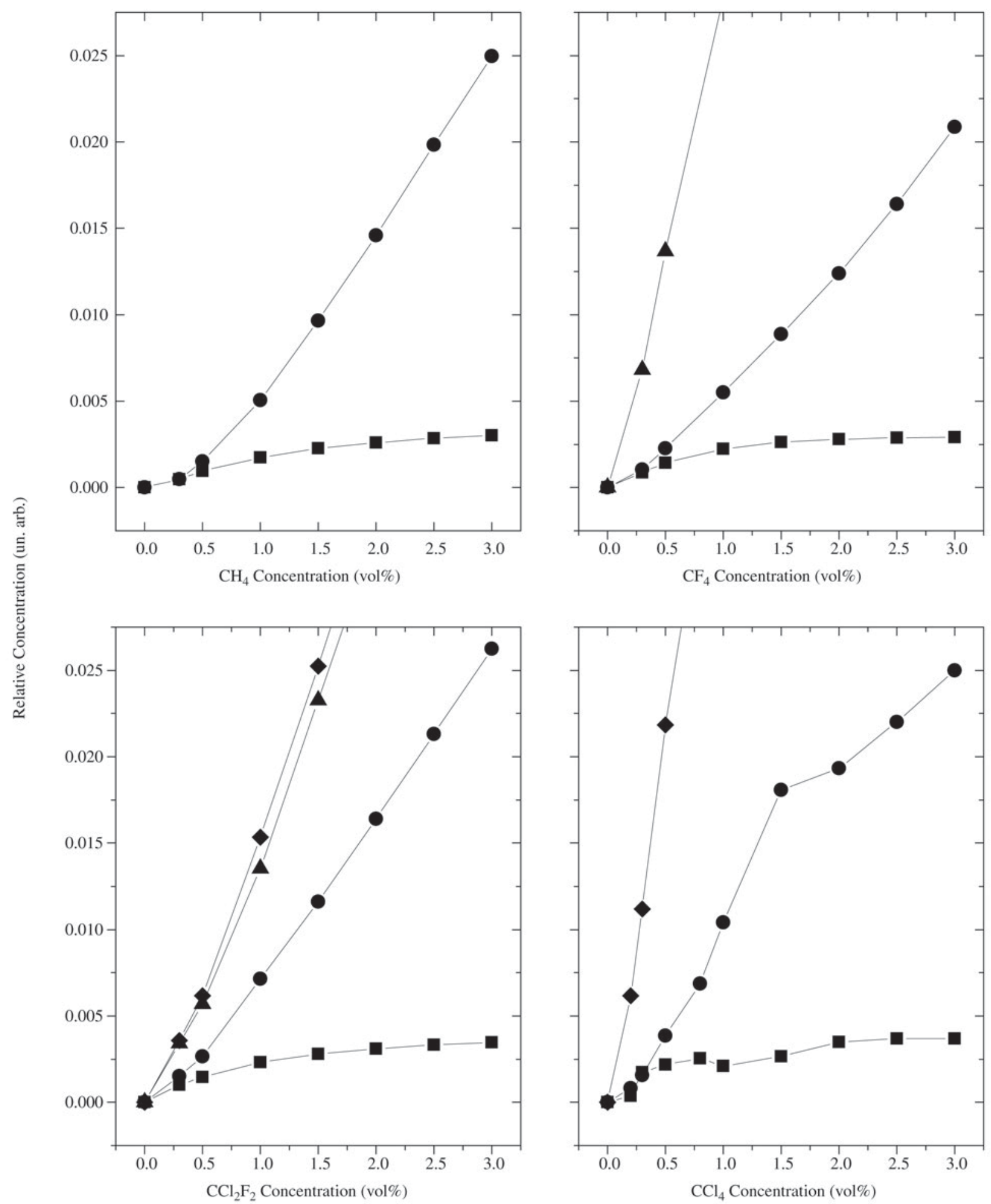

Figure 2. Relative concentration of the stable species in the exhaust gas as a function of concentration in the inlet gas of, respectively, $\mathrm{CH}_{4}$, $\mathrm{CF}_{4}, \mathrm{CCl}_{2} \mathrm{~F}_{2}$ and $\mathrm{CCl}_{4}$, in mixture with hydrogen. $\square \mathrm{CH}_{4} ; \mathrm{C}_{2} \mathrm{H}_{2} ; \mathbf{\Delta} \mathrm{HF} ; \mathrm{HCl}$ 
of the halocarbons into hydrocarbons. Independent experiments in a hot filament reactor have shown that the conversion is very fast.

In spite of all the stable species observed by mass spectrometry in the reactor be the same ones, and in amounts very similar to observed with a $\mathrm{CH}_{4} / \mathrm{H}_{2}$ mixture, except for the presence of the acids, these influence decisively in the general equilibrium of the process, inducing to the formation of larger amounts of carbon in the solid phase. The diamond growth with these halogen mixtures happens only with carbon concentrations lower than $1 \%$ in the inlet gas mixture. Films of good quality are only obtained with carbon concentrations smaller than $0.5 \%$, while, with mixtures of $\mathrm{CH}_{4} / \mathrm{H}_{2}$, it is possible to grow diamond of good quality up to about $3 \%$ of carbon. Besides that, with the mixtures with halogen containing more than $1 \%$ of carbon there is soot deposition on the coldest parts of the reactor, and above $3 \%$ the walls of the reactor are quickly grown dark.

\subsection{Experiments with mixtures containing halogens and oxygen}

With the addition of oxygen to the mixtures containing halogen, the objective is to increase the solubility of the carbon in the gas phase, in the attempt to eliminate the negative aspect of these mixtures and to promote the growth of diamond of good quality at larger carbon concentrations and, take advantage of its main quality, that is the generation of excess atomic hydrogen.

Actinometry experiments proved, for all the mixtures, that the addition of oxygen, not only maintained the condition of production of excess atomic hydrogen, but they also increased its concentration. Figure 3 shows as example the result obtained with $\mathrm{CH}_{3} \mathrm{Cl}$. With the other halogen it was obtained a still larger relative increase of the concentration of atomic hydrogen, while for mixtures of $\mathrm{CH}_{4} / \mathrm{H}_{2}$ occurred a decrease of the $\mathrm{H}$ concentration.

The mass spectrometry done with the addition of oxygen is shown in Fig. 4. It shows, besides the formation of hydrocarbons and of the respective acids (not shown in the figure), the formation of water and carbon monoxide. The situation is very similar for most cases, being comparable to what happens with the addition of oxygen in $\mathrm{CH}_{4} / \mathrm{H}_{2}$ mixtures.

The addition of oxygen reduces hydrocarbon concentrations and there is the formation of $\mathrm{CO}$. This hydrocarbons transformation into $\mathrm{CO}$ tends to saturation for $\mathrm{O}_{2}$ concentrations larger than half of carbon concentration. The reason for that is the high stability of $\mathrm{CO}$ in the diamond growth conditions. In the case of $\mathrm{CCl}_{4}$ the results are less reliable due to the larger experimental difficulties of controlling the flow and the concentrations of it vapor.

The same behavior of Fig. 4 is obtained by the increase of the halocarbon concentration in the inlet gas, but increasing the initial hydrocarbon concentration and moving the

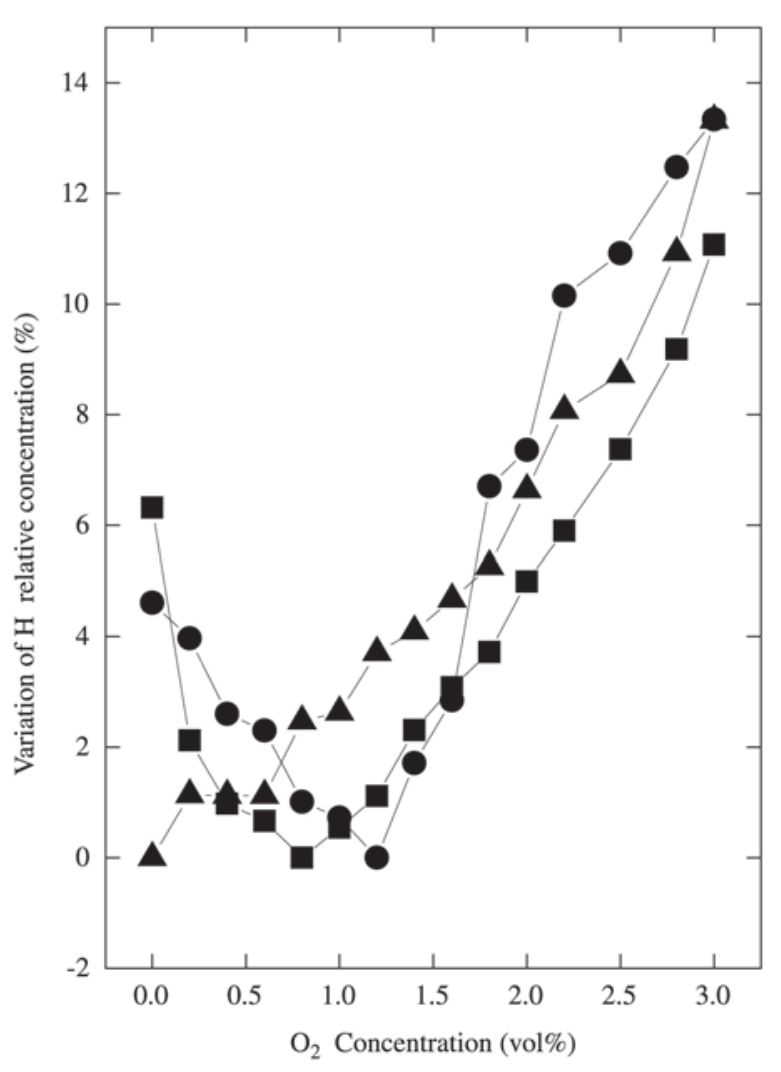

Figure 3. Variation of atomic hydrogen relative concentration with oxygen addition in three different $\mathrm{CH}_{3} \mathrm{Cl} / \mathrm{H}_{2}$ mixtures. $\Delta 0.5 \mathrm{vol} \% \mathrm{CH}_{3} \mathrm{Cl} ; \mathbf{v o l} \% \mathrm{CH}_{3} \mathrm{Cl} ; 2 \mathrm{vol} \% \mathrm{CH}_{3} \mathrm{Cl}$.

point at which the tendency of saturation of the $\mathrm{CO}$ concentration begins.

\subsection{Diamond growth with mixtures containing halogens and oxygen}

In the growth experiments in mixtures containing halocarbons and oxygen, it was obtained a generalization of the result in which good quality diamond growth was obtained with a mixture of $1.5 \% \mathrm{CCl}_{4}+0.5 \% \mathrm{O}_{2}$ in $\mathrm{H}_{2}$. Basically, film of good quality is obtained if the difference between the concentrations of the halocarbon and of $\mathrm{O}$ is of the order or smaller than $0.5 \%$. The quality of the film worsens quickly if this difference approaches $1 \%$. If the difference approaches zero, or the concentration of $\mathrm{O}$ is larger than the concentration of the halocarbon there is no diamond growth. Figure 5 summarizes these results. Comparing with the Bachmann diagram ${ }^{16}$, for mixtures of hydrocarbon, oxygen and hydrogen, the growth points are also around the $\mathrm{CO}$ tie line, but with a much narrower range of growth of good quality films.

Even in conditions of diamond film growth, there is the formation of carbon film on the cold walls of the reactor. 

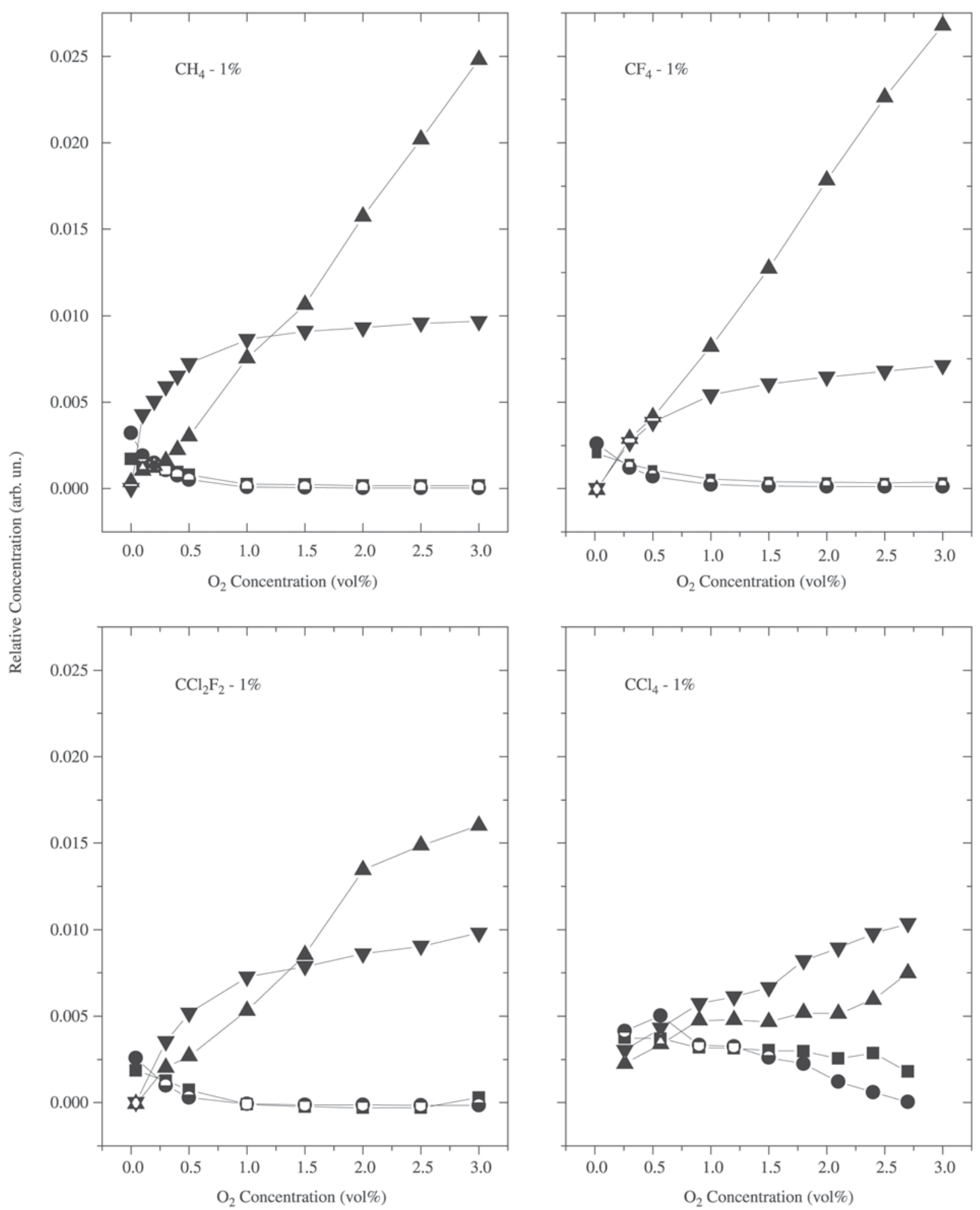

Figure 4. Relative concentration of the stable species in the exhaust gas as a function of oxygen concentration in the inlet gas for mixtures of $1 \mathrm{vol} \% \mathrm{CH}_{4}, 1 \mathrm{vol} \% \mathrm{CF}_{4}, 1 \mathrm{vol} \% \mathrm{CCl}_{2} \mathrm{~F}_{2}$ and $1 \mathrm{vol} \% \mathrm{CCl}_{4}$ in hydrogen, respectively. $\mathrm{CH}_{4} ; \mathrm{C}_{2} \mathrm{H}_{2} ; \boldsymbol{\Delta} \mathrm{CO} ; \boldsymbol{\nabla} \mathrm{H}_{2} \mathrm{O}$. 


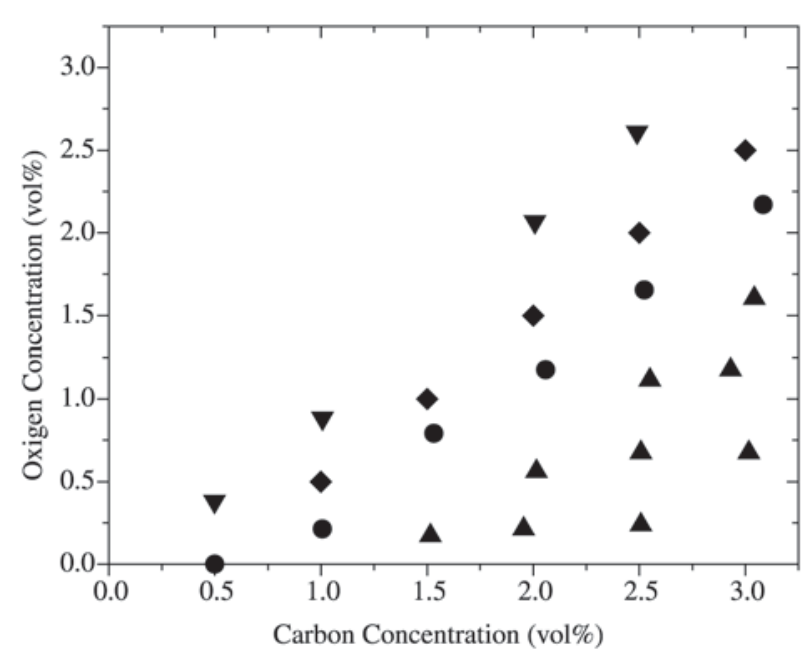

Figure 5. Summary of the growth regions as a function of carbon and oxygen concentrations in halocarbon/oxygen/hydrogen gas system. $\boldsymbol{\Delta}$ Non-diamond carbon; $\boldsymbol{O}$ pour quality diamond; $\bullet$ good quality diamond and $\boldsymbol{\nabla}$ no growth.

This turns unviable the realization of the experiment for long periods, indicating that the presence of oxygen doesn't inhibit the formation of carbon in the solid phase in the most distant areas of the plasma.

In relation to the diamond growth rate there was little variation. For various mixtures tested, in which there was diamond growth, the growth rate was always between 1 and $2 \mu \mathrm{m} / \mathrm{h}$. There was no tendency to increase with the increase of the carbon concentration. As in these experiments the increase of carbon concentration (introduced with the halocarbon) implicates in an increase of the atomic hydrogen concentration in the gas phase (according to Fig. 1), it could be expected an increase of the growth rate. Probably, as the growth range is very narrow around the $\mathrm{CO}$ tie line, only small amounts of carbon just contribute to the growth, and the growth rate is limited by the carbon supply for the process.

\section{Conclusion}

In this work we presented a wide study of diamond growth with halogens, involving four different halogen gases and in comparison with the growth with the conventional $\mathrm{CH}_{4} / \mathrm{H}_{2}$ mixture. A better control of the plasma conditions was obtained by evaluation of the emission lines of the actinometer (argon). This control enabled more reproducible results of the relative atomic hydrogen concentration as observed by the three atomic hydrogen emission lines $\left(\mathrm{H}_{\alpha}\right.$, $\mathrm{H}_{\beta}$ and $\mathrm{H}_{\gamma}$ ). With this control actinometry can be considered a reliable technique for atomic hydrogen analysis, even under very reactive gas phases containing halogens.

Atomic hydrogen relative concentration increases con- siderably with the addition of halogens to the gas phase. Mass spectrometry of the exhaust gas have shown that halocarbons convert very fast to hydrocarbons and the acids $\mathrm{HF}$ and/or $\mathrm{HCl}$, reaching an equilibrium concentration of hydrocarbons that is relatively independent of the halocarbon used. The growth of good quality diamond with halocarbon/hydrogen mixtures occurs only for low carbon concentration of less than $1 \mathrm{vol} \%$ in the inlet gas.

The oxygen addition to halocarbon/hydrogen mixtures was effective in increasing carbon solubility in the gas phase, since growth at higher carbon concentrations were observed. A further increase on relative atomic hydrogen concentration was observed by actinometry. The mass spectrometry reveals that a new equilibrium gas phase is obtained by the conversion of the hydrocarbons to $\mathrm{CO}$. The very high stability of $\mathrm{CO}$ in the gas phase is responsible for the higher carbon solubility. The growth experiments, however, do not show any advantage in growing with halocarbon/oxygen/hydrogen mixtures. Growth conditions are limited to a very narrow range in which good quality diamond is obtained if the difference between the concentrations of the halocarbon and of $\mathrm{O}$ is of the order or smaller than $0.5 \%$. Otherwise, if the carbon content is higher the quality decreases and if the $\mathrm{O}$ content is higher there is no growth.

From this study we conclude that halogens are not, per se, eligible for diamond growth. All the possible advantages, as the higher production of atomic hydrogen, have been suppressed by the low carbon solubility in the gas phase, even when oxygen is added. Besides that, it brings many difficulties to the experiments because of the high corrosion by $\mathrm{HF}$ and $\mathrm{HCl}$. However, some particular experiments with the addition of small amounts of $\mathrm{CF}_{4}$ to a conventional $\mathrm{CH}_{4} / \mathrm{H}_{2}$ mixture have shown many advantages, particularly for substrates that react with the fluorine containing gas phase, as $\mathrm{WC}-\mathrm{Co}^{18}$ and $\mathrm{Si}_{3} \mathrm{~N}_{4}{ }^{19}$ sintered substrates.

\section{References}

1. Angus, J.C. Annu. Rev. Mater. Sci., v. 21, p. 221, 1991. 2. Trava-Airoldi, V.J.; Corat, E.J.; Baranauskas, V. Key Engin. Mater., v. 195, p. 138-140, 1998.

3. Spear, K.E.; Dismuskes, J.P. Emerging CVD Science and Technology. The Electrochemical Society Series, John Willey and Sons, New York, 1994.

4. Goodwin, D.G.; Butler, J.E. Theory of Diamond Chemical Vapor Deposition.

5. Frenklach, M.; Wang, H. Phys. Rev. B, v. 43, p. 1520, 1991.

6. Spitsyn, B.V.; Bouilov, L.L.; Alexenko, A.E. Diamond Relat. Mater., v. 8, p. 1371, 1999.

7. Patterson, D.E.; Chu, C.J.; Bai, B. J.; Komplin, N.J.; Hauge, R. H.; Margrave, J.L. in Proceedings of the $2^{\text {nd }}$ Intern. Symp. On Diamond Mater., Ed. by A.J. Purdes, B.M. meyerson, J.C. Angus, K.E. Spear, R.F. Davis and 
M. Yoder. The Electrochemical Society, Inc., Washington, DC, USA, p. 3, 1991.

8. Ruder, R.A.; Hudson, G.C.; Posthill, J.P.; Thomas, R.E. Markunas, R.J. Appl. Phys. Lett., v. 59, p. 791, 1991.

9. Hong, F.C.N.; Hsieh, J.C.; Wu, J.J.; Liang, G.T.; Hwang, J.H. Diamond Relat. Mater., v. 2, p. 791, 1993.

10. Baranauskas, V.; Fukui, M.; Rodrigues, C.R.; Parizotto, N.; Trava-Airoldi, V.J. Appl. Phys. Lett., n. 60, p. 1567, 1992.

11. Corat, E.J.; Trava-Airoldi, V.J.; Leite, N.F.; Nono, M.C.A.; Baranauskas, V. J. Mater. Res., v. 32, p. 941, 1997.

12. Corat, E.J.; Mendes de Barros, R.C.; Trava-Airoldi, V.J.; Ferreira, N.G.; Leite, N.F.; Iha, K. Diamond Relat. Mater, v. 6, p. 1172, 1997.

13. Petherbridge, J.R.; May, P.W.; Pearce, S.R.J.; Rosser, K.N.; Ashfold, M.N.R. J. Appl. Phys., v. 89, p. 1484, 2001.

14. Ferreira, N.G.; Corat, E.J.; Trava-Airoldi, V.J.; Leite,
N.F. Diamond Relat. Mater., n. 7, p. 272, 1998.

15. Ferreira, N.G.; Corat, E.J.; Trava-Airoldi, V.J.; Leite, N.F.; Del Bosco, E. Diamond Relat. Mater., v. 7, p.81, 1998.

16. Bachmann, P.K.; Hagemann, H.J.; Lade, H.; Leers, D.; Picht, F.; Wierchert, D.I.; Wilson, H. Diamond Chemical Vapor Deposition: Gas Compositions and Film Properties, in Diamond $\mathrm{SiC}$ and Nitride Wide Band Gap Semiconductors, Ed. C.H. Carter Jr., G. Gildenblat, S. Nakamura and R.J. Nemanich, MRS 339, p. 267, 1994.

17. Gicquel, A.; Chevnevier, M.; Hassouni, K.; Tserepi, A.; Dubus, M. J. Appl. Phys., v. 83, p. 7504, 1998.

18. Trava-Airoldi, V.J.; Nobrega, B.N.; Corat, E.J.; Del Bosco, E.; Leite, N.F.; Baranauskas, V. Vacuum, v. 46, p. 5, 1995.

19. Silva, V.A.; Silva, C.R.M.; Corat, E.J. Diamond Relat.Mater., v. 10, p. 2002, 2001. 